\title{
Teaching Evolution Concepts to Early Elementary School Students
}

\author{
Louis Nadelson • Rex Culp • Suzan Bunn • \\ Ryan Burkhart • Robert Shetlar • Kellen Nixon • \\ James Waldron
}

Published online: 4 July 2009

(C) Springer Science + Business Media, LLC 2009

\begin{abstract}
State and national standards call for teaching evolution concepts as early as kindergarten, which provides motivation to continue developing science instruction and curriculum for young learners. The importance of addressing students' folk theories regarding science justifies teaching evolution early in K-12 education. In this project, we developed, implemented, and researched standards-based lessons to teach elements of evolution (speciation and adaption) to kindergarteners and second graders. Our lessons attended to the students' prior knowledge, and utilized inquiry and modeling to teach and assess their ability to recognize patterns of similarity and differences among organisms. Using their products and comments as evidence, it was apparent the students were able to communicate recognition of patterns and effectively apply their knowledge in near transfer activities, indicating they achieved our learning objectives. This provides support for teaching evolution concepts in the early grades and evidence of the ability for young children to effectively engage in supported inquiry and modeling for learning science.
\end{abstract}

L. Nadelson $(\bowtie)$

Boise State University|,

1910 University Drive,

Boise, ID 83725-1700, USA

e-mail: LouisNadelson@boisestate.edu

R. Culp $\cdot$ S. Bunn $\cdot$ R. Burkhart $\cdot$ R. Shetlar

University of Central Florida,

4000 Central Florida Blvd.,

Orlando, FL 32816, USA

K. Nixon $\cdot J$. Waldron

Orlando Science Center,

777 East Princeton Street,

Orlando, FL 32803-1291, USA
Keywords Science education - Evolution curriculum · Inquiry $\cdot$ Modeling $\cdot$ Elementary school students

\section{Science in the Elementary School Curriculum}

According to national science standards and the science standards of many states, science education should start when children enter kindergarten and remain a significant component of the curriculum throughout the K-12 curriculum (American Association for the Advancement of Science [AAAS] 1993; National Academy of Sciences [NAS] 2008; National Research Council [NRC] 1996; National Science Teacher Association [NSTA] 2002). Yet, there are mixed perspectives of how and when various aspects of science, e.g. evolution, should be included in the elementary curriculum (NRC 2000). There is a range of pedagogical and philosophical perspectives influencing how to approach teaching evolution to early elementary students (Metz 1995). The range of perspectives of early childhood science education raises the question of how effectively early elementary students can learn from lessons structured to teach evolution. We address this question by assessing kindergarten and second grade students' learning in response to biological similarities and differences, concepts that are fundamental to the evolutionary concepts of adaption and speciation.

\section{Teaching Science in Early Elementary Grades}

Regardless of mandates to improve science education for early elementary students, the efforts may not be widely embraced by educators. Eshach and Fried (2005) report reluctance to include scientific concepts in early elementary courses based on the belief that these concepts are too abstract for younger 
students. These beliefs are based on the assumption that children are not cognitively prepared to think abstractly enough to learn science. Using the cognitive development framework of Piaget (Inhelder and Piaget 1958) as a context for determining children's abstract thinking abilities, researchers contend that young children have constrained abilities to think scientifically (Kuhn 1989; Marini and Case 1994). However, Metz (1995) contends that Piaget's work may be misinterpreted, and in fact children with adequate support may be prepared to think and learn about causal and abstract relationships as early as four years of age. Furthermore, Chen and Klahr (1999) report explicit instruction resulting in gains in young learners' ability to reason scientifically and increasing their ability to transfer reasoning to related problems. The works of Metz as well as Chen and Klahr provide support for teaching some fundamental scientific concepts starting in early childhood. Furthermore, the empirical evidence provided by Chen and Klahr and Metz, which is contradictory to the expected capabilities of learner from the traditional Piagetian developmental paradigm, illuminates the tension regarding the science learning capabilities of early elementary students. Additional empirical evidence documenting the capabilities of early elementary student science learning may placate concerns regarding the teaching of complex scientific concepts to young children and ease the tension formed by establishing expectations of learners' abilities based exclusively on a developmental paradigm. Our study provides such evidence.

In the National Academy of Science-sponsored exploration of learning and teaching science in the $\mathrm{K}-8$ curriculum, editors Duschl, Schweingruber, and Shouse (2007) argue that science should be taught in ways that enhance interest and take advantage of advances in cognitive and developmental psychology. Duschl and colleagues contend that complex abstract scientific concepts can be made attainable to young learners through scaffolding (Vygotsky 1978), through increased awareness of scientific situations and the associated vocabulary (Eshach and Fried 2005), and by activating and building upon students' prior knowledge (Bransford et al. 1999).

Supporters of teaching young learners science argue that early exposure to related learning situations allows children to acquire knowledge and experience which are essential for comprehending more abstract scientific concepts (Bransford et al. 1999; Eshach and Fried 2005; NRC 2007). Moving beyond the goals of developing content knowledge, Eshach and Fried (2005) contend that teaching science to early elementary children fosters their inherent curiosity and stimulates the growth of positive attitudes toward science. Furthermore, Kuhn and Pearsall (2000) argue that exposing early elementary students to science content is a useful method for teaching young learners how to think scientifically. Therefore, the more critical question is not whether science should be taught to early elementary students, but instead how science should be taught to these learners and what concepts should be covered. In the light of evidence indicating children may be more capable of complex thinking than traditionally anticipated (NRC 2007; Metz, 1995, 2004; NRC 2007), there is justification for experimenting with the content and instructional approaches associated with the elementary science curriculum to determine what students are capable of learning.

Even so, some concerns about young students' abilities to comprehend abstract and complex concepts are warranted. There are many scientific concepts that take years of advanced study to fully comprehend. For instance, to fully understand the theory of evolution's concept of speciation requires prior knowledge of concepts such as mutation, adaption, and chance (Dawkins 1996; Gould 2002; Miller 1999). Yet, speciation (and other evolution concepts) may be made attainable to young learners by reducing the concept into small, simplified components (Eshach and Fried 2005; NRC 1996, 2007). In summary, the likelihood of young learners gaining an understanding of science concepts, such as those associated with evolution, would be increased by maintaining awareness of their cognitive abilities, capitalizing on their prior knowledge, and teaching a series of interrelated developmentally appropriate lessons.

\section{Why Teach Evolution Science in the Primary Grades}

Unless an individual pursues a post-secondary science degree, most exposure to the science of evolution occurs in the secondary science curriculum (Gross et al. 2005). Until relatively recently, abstract scientific concepts from biological evolution were rarely included in the early elementary science curriculum (Gross et al. 2005, 2007). Yet, research has shown that students begin to develop lasting ideas of science, particularly in biology, at a young age (Kelemen 1999). Many additional studies reveal that young learners develop and retain naïve or folk theories of biology or evolution concepts (Hatano and Inagaki 1994; Inagaki and Hatano 2004, 2006; Solomon 2002; Springer 1996). Once young learners develop conceptions, they tend to retain them, resisting explanations that differ from their perspectives (Au et al. 2008; Solomon and Johnson 2000). The retention of possible misconceptions provides justification for the development of lessons that help young learners develop scientific conceptions early in their education. This is particularly true for concepts like biological evolution that tend to be laden with misconceptions (Miller 1999).

Few published studies report the influence of instructional interventions on young learners' understanding of concepts associated with biological evolution (Au et al. 2008; Solomon and Johnson 2000; Venville and Donovan 2007). However, now that the National Science Standards (NRC 1996) and 
some state science standards (FLDOE 2008) call for increased attention to evolution in the elementary grades, there is even greater warrant to develop, deliver, and investigate the effectiveness of lessons structured to teach young learners evolution concepts.

There has been considerable debate over the relationship between acceptance and understanding of evolution (Smith 1994; Smith and Siegel 2004; Southerland et al. 2001), and a full discussion of this issue is beyond the scope of this project. Regardless, it is apparent that waiting to introduce abstract scientific concepts until high school has not been a particularly effective strategy. Over the past 30 years, the percentage of US citizens that accepts the scientific explanation of evolution has hovered at approximately $30 \%$ (Gallup 2008). The lack of significant changes in acceptance and understanding of evolution suggests that the current science education curriculum has not been particularly effective at teaching this concept. Research has shown a significant positive correlation between the acceptance of evolution and knowledge of evolution (Nadelson and Sinatra 2008). We can infer from the relatively low level of acceptance that there is a corresponding low level of knowledge. As stated previously, evolution is an abstract concept that requires substantial background knowledge to grasp, which suggests that early exposure to aspects of biological evolution may be critical to the development of deep understanding (National Academy of Sciences 1998; NSTA 2002; Spillane and Callahan 2000). This provides additional justification for exploring content and instructional approaches for teaching theory of evolution concepts in the elementary science curriculum.

\section{Teaching Elementary Science}

Advocating for a sustained emphasis on science in grades $\mathrm{K}-12$ has been accompanied by recommended modifications to both science curriculum and instruction. A major shift in the organization of science curriculum has been a move from traditional discipline-based foundations for content to a thematic approach that utilizes unifying concepts, such as evolution or energy (FLDOE 2008; NRC 1996, 2007). As a result of this organizational shift in science curriculum many state science standards are now structured using unifying concepts, starting in the early elementary grades (FLDOE 2008). Recommendations for modifications to instruction call for increased emphasis on inquiry-based activities (Metz 2004; NRC 2000; NSTA 2002) and opportunities for scientific modeling (Lehrer and Schauble 2004). The motivation for changing instructional approaches is based on the research that suggests that when students engage in activities to learn science in a manner that is similar to the work of professional scientists they gain a greater understanding of science (Duschl and Grady 2008).
Yet, as efforts to increase the quality of science education take place, the amount of time spent on teaching science at the elementary level has continued to decline (Center on Educational Policy 2008), which constrains abilities to meet the goals of the national and state science education standards. The Center on Educational Policy reports that increased time spent on math and English language arts instruction in elementary education has resulted in decreased time spent on teaching science, the visual arts, and the social sciences. This provides justification for taking a multidisciplinary approach in the development and teaching of science curriculum. By integrating science content with lessons in visual arts, there are increased opportunities for students to learn content from both domains and increased opportunity to respond to the NRC (2007) recommendation that science should be taught in a manner that enhances student interest.

Teachers may not eagerly embrace a multidisciplinary design approach for teaching science (Skamp and Mueller 2001; Tosun 2000; Yates and Chandler 2001), but as Levitt (2001) reports, teachers tend to be open to modifications in their approaches to teaching science when provided with useful models. The need for models of science curriculum in the elementary school curriculum provides a motivation for promoting the development, delivery, and research of science curriculum for early elementary students.

Responding to research-based content and instructional recommendations for teaching early elementary students science is a challenging process. Developing research-based standards-focused science curriculum requires knowledge of (1) the science education literature, (2) awareness of the needs of early elementary learners, and (3) an understanding of the science content. We took on this challenge and put together a team of teachers, science educators, and educational researchers to bring evolution education to elementary students. In this project, university faculty, science center educators, and elementary school teachers collaborated to create, instruct, and research developmentally appropriate, inquiry-based, high interest, standards-focused science curriculum designed to teach organism similarity and differences - precursor concepts of speciation and adaptation - to early elementary grade students. We designed the inquiry of these lessons to be guided and structured to be classified somewhere as a level 0 to level 1 inquiry using Schwab's classification system (Schwab 1962).

\section{Purpose}

The purpose of this project was to develop and test evolutionary biology lessons for kindergarten and second grade students. This project involved the collaboration of university faculty from the College of Education, College of Arts and Humanities, College of Hospitality Management, and 
College of Sciences; educators from a metropolitan science center; and teachers and administrators from local elementary schools. A significant goal of this project was to address early elementary science standards for teaching evolution through the design of lessons that utilized research-supported best practices and developmentally appropriate curriculum and instruction. Our lessons were developed based on selected kindergarten and second grade science standards (FLDOE 2008) that focused on evolutionary theory concepts.

The theory of evolutionary science standard selected for the kindergarten level stated: Observe and describe similarities and differences among different types of plants and among different types of animals (FLDOE 2008). Since this science standard focuses on the evolutionary theory concept of speciation, we determined our goal was to teach students about how organisms might be related beyond their outward appearance. To achieve this standard in the development of our lesson required us to understand what biological systems or structures kindergarteners could recognize as similar and different. Furthermore, the lesson development also necessitated knowledge of the abilities of kindergarteners to model similarities and differences, and an awareness of how to effectively assess their learning.

The theory of evolutionary science standard selected for the second grade level stated: Recognize some organisms that lived long ago are similar to existing organisms today, but some have completely disappeared (FLDOE 2008). Using the science standard's relationship to the evolutionary theory concepts of speciation and adaptation, we determined our goal was to teach the second graders about how present-day organisms share features, have unique features, and features in common with ancient organisms. To achieve the goal of meeting this standard required us to be familiar with secondgrade students' knowledge of organisms living today and long ago. In addition, our lesson development also required awareness of second graders' abilities to model organism structures, and an understanding of how to effectively assess the students' perceptions of the similarities and difference of organisms alive today with those that lived long ago.

Based on our goals and objectives, we developed the following research hypothesis and questions, which we used to guide our investigation. We hypothesized that our lessons would allow early elementary students to achieve the selected science standards because our lessons would induce high levels of student engagement through (1) inquiry; (2) the application of prior knowledge; and (3) the development of models, which have been reported to be effective for teaching young learners science.

The questions motivating this investigation were:

- What do student products tell us about their learning and understanding of science concepts related to the foundational concepts of speciation and adaptation?
- Are science lessons that are structured to include inquiry and model construction activities effective for teaching organism similarities and differences to early elementary students?

- Are early elementary students capable of learning the evolutionary biology concepts fundamental to comprehending speciation and adaption?

\section{Method}

Participants

The students participating in this pilot project were recruited from two urban elementary schools with diverse student populations. We recruited 30 kindergartners for participation from one of our cooperating schools (approximately $22 \%$ of the school's kindergarten population), with 16 in one classroom and 14 in a second classroom. We recruited 34 second graders for participation from a second school (approximately 29\% of the school's second grade population), with 16 from one classroom and 18 from a second classroom.

We did not gather individual demographic information from the students. The decision to omit gathering of individual demographic information eased the authorization to conduct this research by the institutional review board (IRB) and the cooperating school district's Office of Research. In place of individual demographic information we used composite demographic information from the school as a whole and inferred our sample based on these data. The demographic data for each of the schools were extracted from the school district's web site.

In addition to reporting ethnic diversity and free and reduced lunch, we also reported special needs populations. Our two participating schools used an inclusion model for their special education students, creating the possibility that learning disabled and gifted and talented students were included in our study sample. The school demographics and the inferred class demographics are displayed in Table 1.

Lessons of Evolution

Using our selected science learning standards and our research and development goals as guides for lesson development, the university faculty team and science center educators collaborated to design two developmentally appropriate science lessons, one for each grade level. The development process began with a search for web-based and printed resources related to both our selected science standards and corresponding grade levels. Our intention was to use extant lessons as models for our lesson development. 
Table 1 School demographics for the kindergarten and second grade schools

\begin{tabular}{|c|c|c|c|c|}
\hline Demographics & Kindergarten school & Inferred kindergarten sample & Second grade school & $\begin{array}{l}\text { Inferred grade } \\
\text { two sample }\end{array}$ \\
\hline Student Population & 896 & 30 & 702 & 34 \\
\hline Students eligible for free or reduced lunch & $32 \%$ & 10 & $18 \%$ & 6 \\
\hline Students with disabilities & $21 \%$ & 6 & $14 \%$ & 5 \\
\hline Gifted students & $5 \%$ & 2 & $18 \%$ & 6 \\
\hline English language learners & $14 \%$ & 4 & $5 \%$ & 2 \\
\hline White & $48 \%$ & 14 & $76 \%$ & 26 \\
\hline Black & $31 \%$ & 9 & $13 \%$ & 4 \\
\hline Hispanic & $9 \%$ & 3 & $6 \%$ & 2 \\
\hline Asian/Pacific Islander & $8 \%$ & 2 & $3 \%$ & 1 \\
\hline Multiracial & $4 \%$ & 1 & $3 \%$ & 1 \\
\hline American Indian/Alaskan Native & $<1 \%$ & 0 & $<1 \%$ & 0 \\
\hline
\end{tabular}

We were not able to locate any extant lessons that were fully consistent with our research goals. The dearth of published lessons and resources appropriate for teaching evolution science to young learners may be reflective of the relatively recent inclusion of evolution science standards in the early elementary curriculum. From the internet and grade level science textbooks we were able to locate several analogous age/developmentally appropriate science lessons which were used as models for properly structuring and situating our lesson activities. These resources were also used as catalysts for team discussions of the suitable content and instruction for our lessons.

During our lesson development we decided that the science educator from the science center would lead the class activities, and the researchers would work with the teachers to facilitate the learning processes when needed. These roles also freed the researchers to move about and observe student engagement, ask questions to determine student perceptions, and take photos of the students' products.

\section{Kindergarten Lesson-Similar and Different}

Again the goal for the kindergarten lesson was the exploration of organisms' similarities and differences, which are key concept for understanding speciation. After some discussion, we determined to use the forelimb of vertebrates as a context for the lesson. The forelimbs of many vertebrates are remarkably similar and yet discernibly different, which provides an ideal condition for teaching the similarities and difference of organisms. Furthermore, we recognized the importance of using organisms that were familiar to the kindergarteners, so that the students would be able to utilize their prior knowledge. Therefore, we selected a variety of vertebrate organisms from the local environment that were readily recognizable by young learners. Our final list of vertebrates included: manatee, bat, monkey, cat, and alligator. We purposefully omitted humans to avoid the possibility of controversy, but at the same time, we anticipated that the students may infer the similarities and differences between humans and the monkey. We then located illustrations of the bones of the forelimb for each of these organisms. Each illustration displayed the corresponding organism's five digits, metacarpals, carpals, radius, ulna, and humerus. Our lesson development relied on the concept of similar forelimb bone anatomy and the corresponding diagrams and culminated with three related activities designed to achieve our selected science standard.

The first activity of this lesson introduced the students to the similarities and differences of animal bone anatomy. In this activity, the students (working in pairs) viewed fullpage illustrations of the forelimb bone anatomy of our five selected animals. Our science educator then instructed the students to identify what was the same about the arrangement and number of bones and what was different about the arrangement and number of the bones in the illustrations. The science educator instructed the students to color the similar features among the pictures using the same colors to show each similarity. The researchers and teachers both facilitated and observed this activity.

The second activity of this lesson involved the transfer the knowledge from the first activity toward the development of a forelimb model. In this activity our science educator asked the students to work individually (in small groupings) to create a two-dimensional model of the bones of a dog forelimb using Popsicle sticks and tongue depressors to represent the major bones. A template outlining of the exterior of a dog forelimb provided the necessary structure and guidance for the students. The 
activity instructions reminded the students to use their knowledge of dogs' paws and to apply what they had just learned about the similarities and differences of forelimb bones of five selected animals. The researchers and teachers facilitated and observed this activity.

The third activity required the application of student acquired knowledge of forelimb bones and was used to determine if students could effectively communicate the function of the joints and bones of the dog forelimb through illustrations. In this activity, we asked the students to individually draw a moving dog. Our science educator reminded the students to think about the different bones and structures but did not provide them with detail, as we intended to use this activity as an assessment of reasoning abilities and their ability to communicate what they had learned in the two previous activities. During this activity the researchers and teachers acted as observers.

The lesson closed with our science educator providing a summary of the similarities and differences of forelimbs. The students were then encouraged to think of other situations of similarities and differences among plants and animals. Appendix A includes the lesson plan for kindergarten children.

\section{Second Grade Lesson—Ancient and Living Organisms}

Once more, the goal for our second grade lesson was the exploration of the similarities and differences in organisms, which is fundamental to conceptualizing speciation and adaption. In this situation both ancient and living organisms were explored. After some discussion and reflection on both our standard and student population we determined that this lesson would focus on the comparative anatomy of ancient and living birds. We selected birds as the group of organisms for study because they are familiar to students. Furthermore, it is rather easy to demonstrate that contemporary and ancient birds share some features as well as have different attributes. We decided the lesson should begin with an exploration of the similarities and differences of air and aquatic birds. This approach allowed us to capitalize on the students' prior knowledge and established a foundation for identifying the similarities and differences between contemporary birds and the ancient aquatic bird Hesperornis (see Appendix B for more information about this organism). The final version of our lesson contained three distinct but related learning activities.

The goal of the first activity was to frame the notion of biological form and function, a fundamental concept for recognizing the similarities and differences in ancient and living organisms. The activity stimulated the students' prior knowledge of birds and provided an opportunity for them to apply that knowledge to the construction of a model of a bird. This activity began with the students (as a class) sharing their knowledge of the anatomical features and behaviors of birds, facilitated by the science educator from the science center. The responses from the students were listed on the classroom whiteboard. The list was used to review the anatomical parts of birds, such as wings, feet, beaks, eyes, and feathers. Following this review, a diverse collection of objects was distributed to the students, and they were instructed to work in small groups (of about two to four students) to create a model of a contemporary flying bird, based on their shared knowledge of birds. The researchers and teachers both facilitated and observed this process. Following the creation of their bird models, the students were directed to individually draw an illustration of their birds in the habitat they envisioned the bird would live. A template was provided for the illustration activity. During this activity the researchers and teachers simply observed this process.

The second activity of this lesson was similar to the first, except this time the focus was on aquatic birds. Again, facilitated by the science educator from the science center, the students (as a class) compiled a list of the features of aquatic birds. The features of aquatic birds such as webbed feet and bills for eating fish were reinforced, with emphasis placed on the similarities and differences between aquatic and non-aquatic birds. The students were then instructed to work in pairs to modify their bird models based on their list of aquatic bird features. During this activity the researchers and teachers facilitated and observed this process. Again, once the models were completed the students were directed to individually draw an illustration of their birds in the habitat they envisioned the bird would live on a provided template. Again, during this activity the researchers and teachers simply observed this process.

The third activity was designed to engage students in thinking about the similarities and differences in ancient and living organisms. This activity began with presentation of the ancient organism Hesperornis by the science educator from the science center. The presentation included an illustration of what the animal was hypothesized to look like, along with a fossilized skull model. Students (as a class) were asked to identify features of the bird that were similar and different to contemporary birds. Anatomical features such as webbed feet, vestigial wings, and feathers were discussed, along with hypothesized traits or behaviors such as the possibility of live birth instead of laying eggs and why this behavior may have changed over time. The predicted need for Hesperornis to nest was discussed, along with their hypothesized limited land mobility. Following the discussion and presentation, the students (in their work groups) were given a worksheet that was used to compare the features and behaviors of Hesperornis to contemporary birds. The students were instructed to identify features and 
behaviors which were similar (drawing a line through the term) and those features and behaviors which were different (circling the terms). During this activity the researchers and teachers simply observed the process. The goal of this activity was to determine if the students recognized the similarities and differences in ancient and living organisms. The worksheet of terms provided an additional source of data that was used for assessing student learning and the achievement of our selected science standard. Appendix B includes the lesson plan for second grade children.

\section{Data Collection}

Following approval of the research protocol by the IRB, we contacted two local elementary schools, seeking their cooperation to provide us with an opportunity to pilot our lessons with their students and teachers. The primary goal was to determine the effectiveness of these lessons at meeting the associated science standards. To simplify the process of teaching the lessons, we focused on two kindergarten classrooms at one school and two second grade classrooms at another school. We conducted a site visit prior our lesson implementation and reviewed the curriculum and activities with the teachers and administrator to assure all were sufficiently informed regarding our project. The reception to our project was highly enthusiastic, as was made evident by the requests from nonparticipating teachers to observe the lesson and have access to the instructional materials. Approximately one week before our implementation, we provided copies of our lessons to the cooperating teachers, which allowed them the options of reviewing some of the essential background knowledge with their students. However, these schools had already aligned their science curriculum with the state science content standards; therefore, they had already taught about some fundamentals of anatomy and about birds. The science curriculum for both the kindergartners and second graders was already planned in detail for the academic year, well in advance of our contact with the schools. Therefore, we assumed that the teacher exposure to our lessons did not significantly influence their teaching and the science curriculum.

Our lesson instruction took place on two consecutive days, with one day spent in each school working with a single grade level. We conducted the instruction in two different classrooms in each school, starting in the first classroom shortly after the commencement of the school day and once the lesson was completed, immediately progressed to the second classroom. In an effort to assure implementation fidelity, all lessons were taught as designed. It is important to note that in the four classrooms all students present actively took part in all activities.
To capture as much data about student learning as possible, we used a combination of photography and transcription of student comments and responses to questions. The photos were of student products and did not include faces of the students. All dialogues with students and their comments were written down and not directly recorded. Again, this decision was made to assure institutional authorization for our study. Photocopies of student drawings were made on site, student work was then returned, and the names on the photocopied papers were masked.

\section{Results}

The analysis of our data was framed in the context of our research questions. We sought to determine if our lessons were effective for teaching evolution, if the students learned the evolution content, and what their products told us about what they learned. Our analysis took place by grade level. We first examined the kindergarten data and then the second grade data. We examined the dialogue, photos, and illustrations to determine gathered evidence to answer our research questions. In an effort to achieve accurate analysis, student data was examined independently by at least two of the researchers, providing an opportunity to determine interrater reliability. Agreement was attained for approximately $85 \%$ of the data. In cases of disagreement, discussion took place until a common understanding was achieved.

\section{Analysis of Kindergarten Data}

The lesson opened with one of the science educators from the science center asking the students (as a class) to respond to the question "What do alive things do?" Without further prompting the students raised their hands and quickly answered aloud with: "moving," "eating," and "drinking." The students offered several additional responses very similar to these descriptors. With some prompting the students (as a class) also identified reproduction ("making more") and elimination ("going to the bathroom"). The discussion then focused specifically on animal movement as our science educator asked the students "What do animals needed to move?" The students, as a group, responded immediately with "legs," "feet," "bones," and "muscles." The identification of bones and muscles as essential for motion indicated that the students had prior knowledge of fundamental anatomy, which was deemed essential for grasping the similarities and differences concepts of the lesson.

As the lesson progressed to the structural patterns of animal forelimbs activity, the students were given the forelimb illustration for each of the five selected animals. Through 
dialogue with small groups of students, it was apparent that they recognized the illustrations to be the bones of a leg or arm. Furthermore, they were readily able to recognize the patterns in the bone structure and identified the similarities in the single upper bone (humerus), the two mid-arm or leg bones (radius and ulna), and five fingers or toes (phalanges). They were less able to recognize the anatomical differences of the forelimbs, such as the variations in the proportions and orientations of the forelimb bones and joints.

The collections of completed illustration assignments revealed that the majority of the students was able to readily identify some patterns of similarities of the forelimbs. A typical set of drawings representative of those who completed the assignment correctly is presented in Fig. 1. The student who completed the activity in Fig. 1 used one color to circle the fingers, another color to circle the radius and ulna, and a third color to represent the humerus, which makes it evident that the student identified a pattern of similarity in the illustrations of bone anatomy. Approximately $20 \%$ of the students were either not able to detect and communicate a pattern of similarity within the illustrations, or simply did not understand the assignment instructions. The student work in Fig. 2 is representative of a product in which the student did not communicate a pattern of similarity in the forelimb bone illustrations. This student used a variety of colors to simply color in a single bone illustration, did not attend to the other illustrations, and did not communicate the recognition of a structural pattern between the different forelimbs. This may indicate that the student did not recognize a pattern or did not understand the activity directions. However, it is interesting to note that this participant used the same color to fill in similar structures within the single illustration which may indicate recognition of a pattern in this specific forelimb.

The identification of differences in the forelimbs was a much more challenging activity. A few students communicated seeing patterns of differences in the sizes and number of

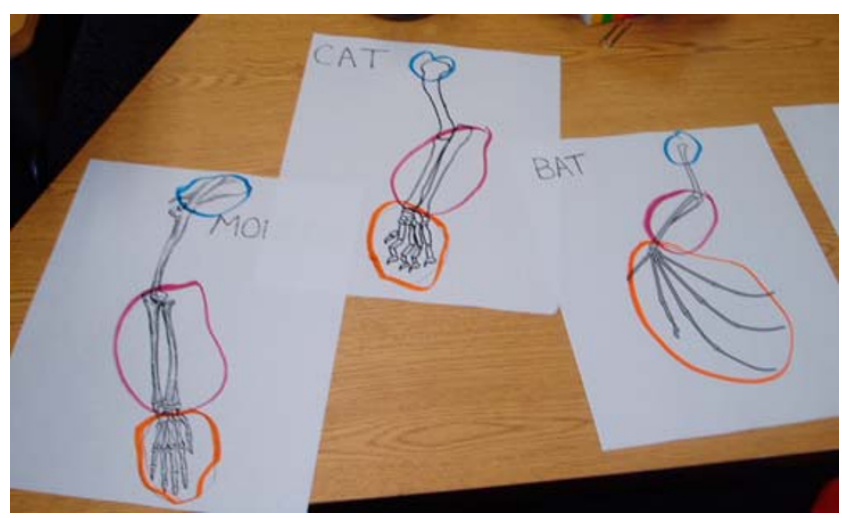

Fig. 1 A student product that communicated the recognition of a pattern of similarity among the forearm illustrations

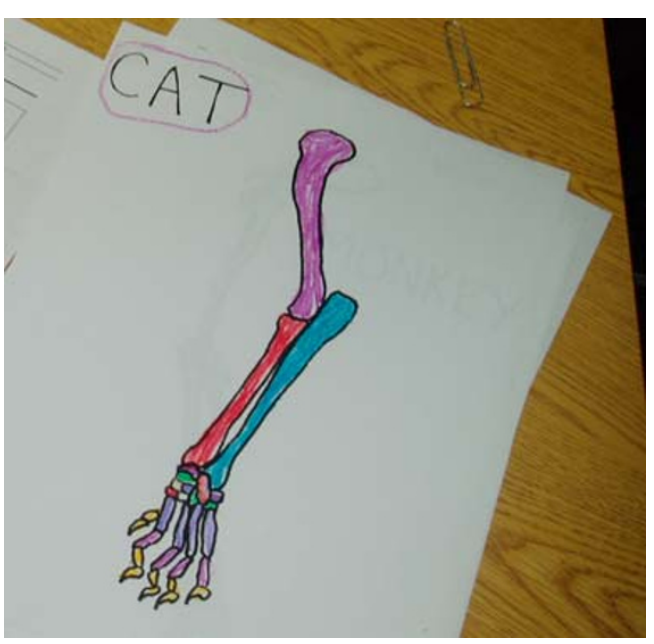

Fig. 2 A student product that did not communicate the recognition of a pattern of similarity among the forearm illustrations

bones in the illustrations. Some also noted some bones seemed fatter (as with the manatee) and longer (as with the bat) than others, indicating a recognition of a pattern of proportional differences. However, most did not seem to grasp the notion that the illustrations were not to scale and therefore, did not consider patterns of differences in the relative size of the forelimbs. Furthermore, dialogue with the students made evident their tendency to focus on the positions of the limbs on the papers as important patterns of difference. It was interesting to find that many of the students perceived the orientation of the forelimb illustrations as being static. This constrained their willingness to rotate the papers in different directions, which might have led to recognition of patterns of difference.

The illustration activity was followed by the model construction of the forelimb bones of a dog assignment. Using different lengths and widths of Popsicle sticks and tongue depressors, each student created his/her own model. An examination of the photographs taken of the models revealed that most students understood that a dog should have at least four toes and some connecting bones in the rest of the leg. The students were reminded to look at the similarities of the bones of the animals in their diagrams. When asked how many bones were connected to the "fingers" the students replied "two." When they were then asked how many bones a dog should have they also replied "two." It took some additional prompting and support for the students to make the connections between the bones in the images and in their arms to the model of their dog forelimbs. However, once they recognized that the diagrams and model were supposed to be similar, most of the students were able to create accurate models of the bones of a dog forelimb (see Fig. 3). This indicates that with support, students were able to transfer the knowledge of forelimb structure from the illustrations to the creation of a model. 


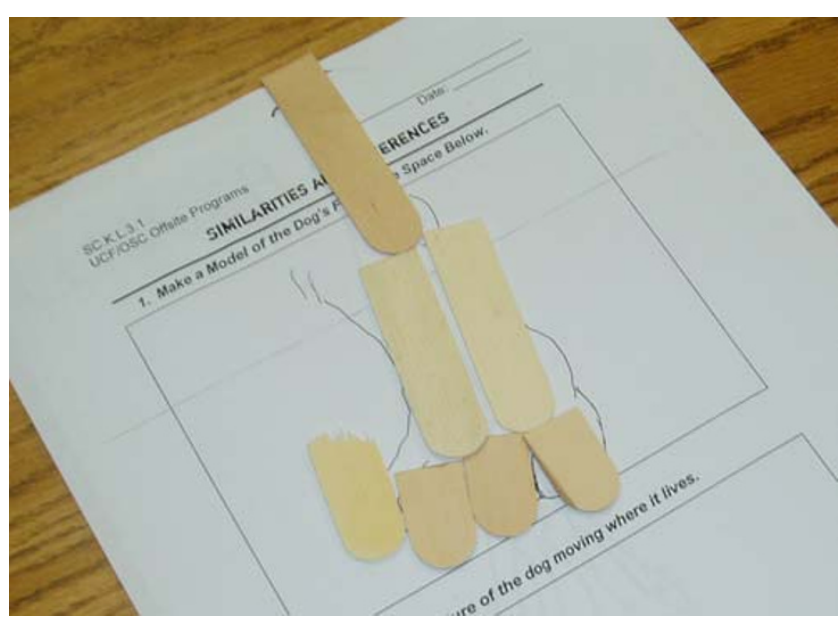

Fig. 3 A student-created model of the bones of a dog forelimb that accurately portrays the fundamental structure portrayed in the illustrations

However, not all students accomplished this task. Some students simply filled the space in the template with the sticks and were attentive to only some parts of the fundamental structures of an animal forelimb (see Fig. 4).

An analysis of the photographs taken of the student models indicates that about $75 \%$ of the students were able to transfer the pattern of a forearm to the development of a dog forelimb model. Some of the participants started out with the correct form, and then influenced by their classmates, modified their models and filled them in with the sticks. When prompted, these students quickly reverted to their previous models.

The final activity instructed the students to draw a dog in motion. The participants' drawings did not appear to depict dogs in motion and therefore, were not effective for determining their ability to transfer of knowledge of the movement or position of the bones in the forelimbs. The

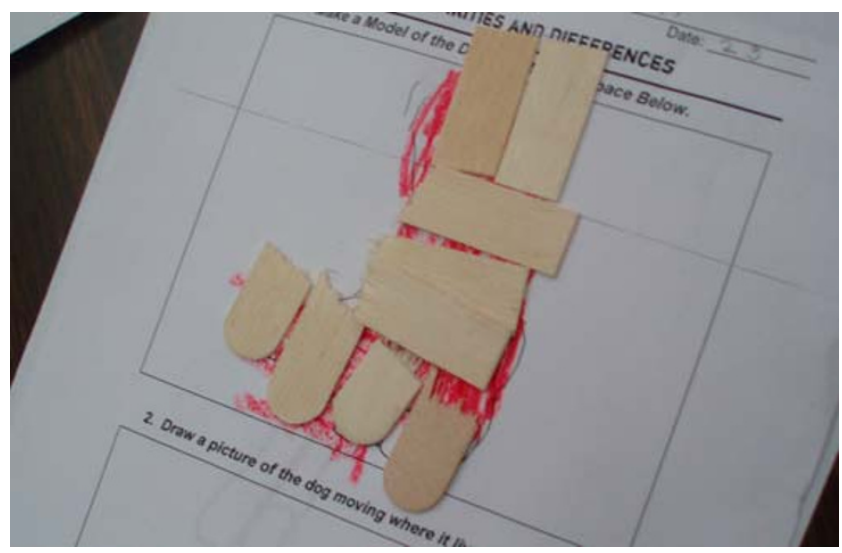

Fig. 4 A student created forelimb model using the sticks to simply fill the provided space drawings are typified by Fig. 5, which indicates that the students did not focus on the leg structure or motion of the dog, but were more concerned with drawing the dog as a whole. The illustrations of the dogs did not appear to be different than those that any kindergarten student may draw. The illustration did not reflect an increased awareness of the structure of a dog forelimb or other anatomical features or details beyond the obvious. This suggests that the detail needed to effectively illustrate the movement or position of the bones in the forelimbs of dogs may be beyond the abilities of kindergarteners, or they may need more support and guidance than we provided.

\section{Analysis of Second Grade Data}

The analysis of the second grade data began with an examination of the list of bird features that the students shared (as a class) in the opening activities led by the science educator from the science center. Their responses included some obvious avian features such as "feathers," "wings," "beaks," and "feet." However, the students also offered additional features that reflected a higher level of sophistication, such as "hollow bones" and "air sacks." Accompanying the list of avian features were behaviors such as "flying," "swimming," "eating," and "making nests." These responses indicated that the participating students had at least fundamental background knowledge of bird structures and functions, and in some cases, an awareness of some of the less obvious features. This was to be expected, since the study of birds is part of the second grade science curriculum, and the students had recently completed the corresponding unit of study.

The students were then led into the activity of creating a model of a bird. Working in small groups, the students were instructed to use the variety of provided items (string, paper clips, pipe cleaners, feathers, popsicle sticks, Styrofoam, etc) to create a model of a bird. The students' models varied widely in size and shape, yet the majority of the students

\section{Draw a picture of the dog moving where it lives.}

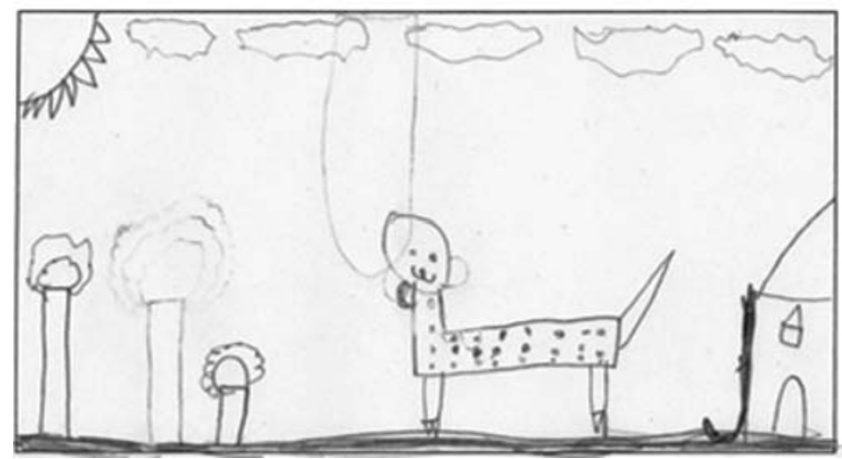

Fig. 5 A typical response to the dog drawing activity 
created bird models that included most of the primary features associated with non-aquatic, flying birds. As the students constructed their bird models, it was apparent that they were more attentive to some structures and less concerned with modeling others. For example, beaks, wings, and tails were more prominent than eyes, feet and legs, and neck (see Fig. 6). This was an interesting occurrence, given the initial activity reviewed all the significant exterior anatomical structures of birds. This outcome indicates that these young learners were more attentive to selected features of birds and therefore, were more likely to recognize the similarities and differences among these particular structures.

Once the students completed their models, they were instructed to draw their bird in the environment in which it lived. The pictures that the students drew of their birds reflected perspectives of birds in flight and perched in trees. This was an expected finding, since birds in the air and in trees are familiar circumstances the students have most likely observed many times. An analysis of the students' illustrations revealed that they included most or all of the external features of a non-aquatic, flying bird (see Fig. 7). This indicates that the students were aware of the multiple exterior features of birds that they did not attend to in the construction of their models. This suggests that the students may be attentive to a wider range similarities and differences in details than was anticipated from viewing their models. It was also interesting to note that many of the students specifically drew their models as an example of a non-aquatic, flying bird in the environment, even when some of the models were considered rudimentary representations of birds.

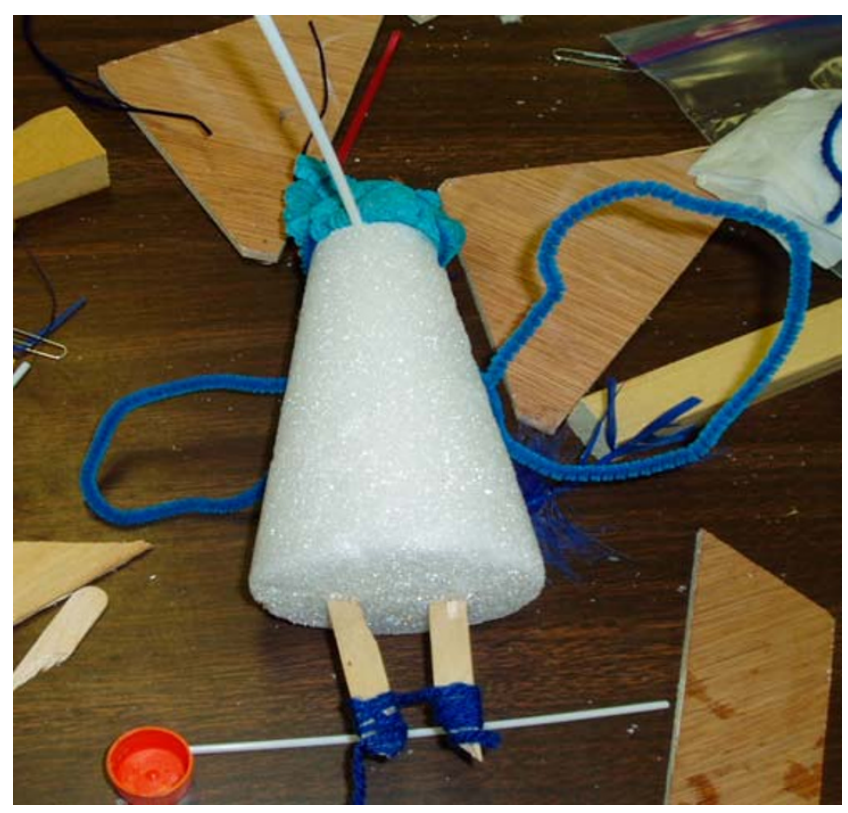

Fig. 6 Photo of a typical non-aquatic bird model created by the second grade participants

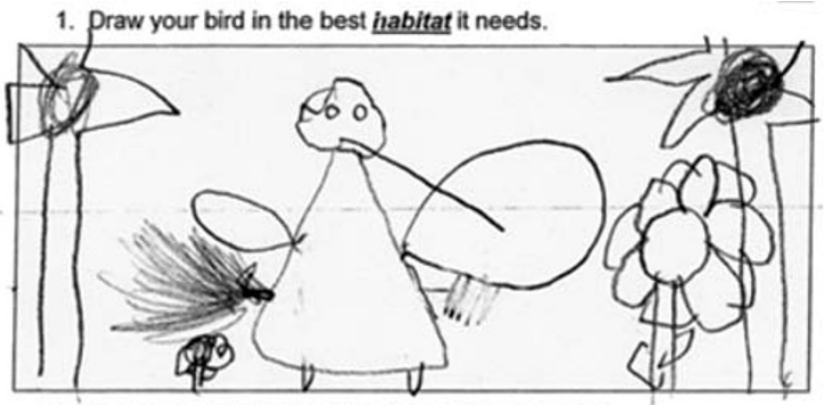

2. Draw your water bird in the best habitat it needs.

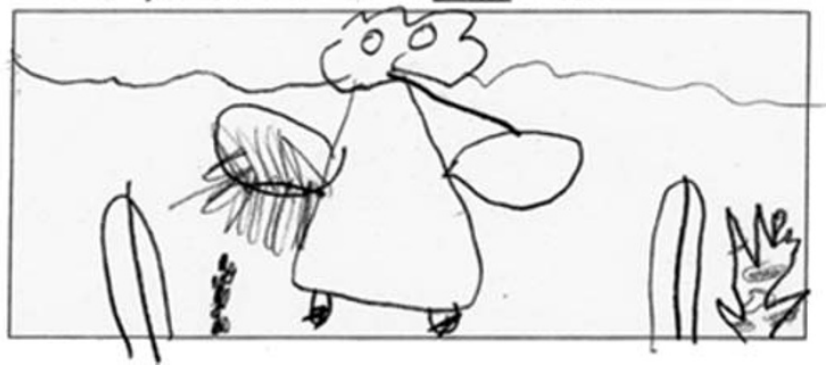

Fig. 7 An illustration of an unmodified bird drawn in an aquatic environment

The next activity began with a classroom discussion of aquatic birds and the features of ancient Hesperornis. This provided a context for students to consider some of the similarities and differences of ancient and contemporary aquatic birds. A model of the fossilized skull and an illustration of Hesperornis provided a foundation for student exploration of the features of this ancient bird. When prompted to list some of the unique features of Hesperornis, the students indentify teeth, wings that could not be used for flight, and feet that are intended to be used for paddling instead of walking or perching. Additional speculative information, such as giving birth to live young instead of laying eggs and the lack of nesting, were also shared. This exercise prompted student recall of their knowledge and awareness of aquatic birds and how those features may be similar or different from the now-extinct Hesperornis and with non-aquatic birds.

Following this discussion, the students were instructed to modify their models to make the bird adapted for an aquatic environment. However, in both class implementations, time constraints limited the opportunity for the students to complete full modifications of their models. So this activity quickly progressed to the drawing assignment. Again, some of the students simply drew their model of their non-aquatic bird in the aquatic environment and did not make any significant modifications to the form in their drawings. However, some subtle changes were apparent in some of the drawings. Most drawings included some sort of flipper foot, a bill instead of a beak, and smaller wings. This indicates that the students 
understood the similarities and differences between the aquatic and non-aquatic birds. Examples of student illustrations can be seen in Figs. 7 and 8 .

Other students communicated a greater difference in aquatic and non-aquatic birds in their drawings. Some students made drawings showing birds swimming, with webbed feet and with teeth. An analysis of the illustrations indicates that the students were aware of the differences and similarities of birds and were able to apply their knowledge as reflected by the modifications of their bird drawings (see Fig. 8). The numbers of relatively unmodified and noticeably modified illustrations were nearly evenly divided, indicating that about half of the students were able to communicate that aquatic birds look different but retain many of the same features of the nonaquatic birds.

Following the creation of the models and the drawing activities, the students were asked to use a worksheet to compare the features of Hesperornis with those of modern birds and determine what they considered to be similar or different. The list included features such as having teeth, feathers, and wings; and behaviors such as walking, nestmaking, and laying eggs. Most students understood and easily completed this activity. The percentage correct for each of the features and behaviors was tabulated (see Fig. 9). It is apparent from these data that the majority of the students was able to recognize the similarities and differences of ancient and living birds. The data revealed that the students were not as sure about the difference of laying eggs and building nests. Since both of these concepts are associated with birds alive today, it is likely the students had difficulty conceptualizing birdlike organ-

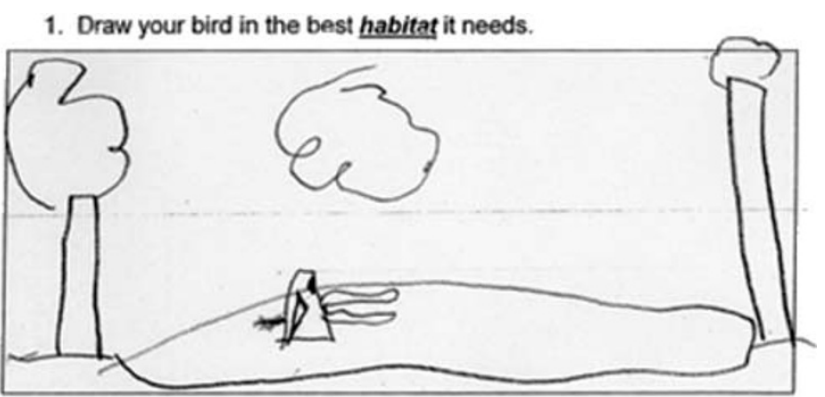

2. Draw your water bird in the best habitat it needs.

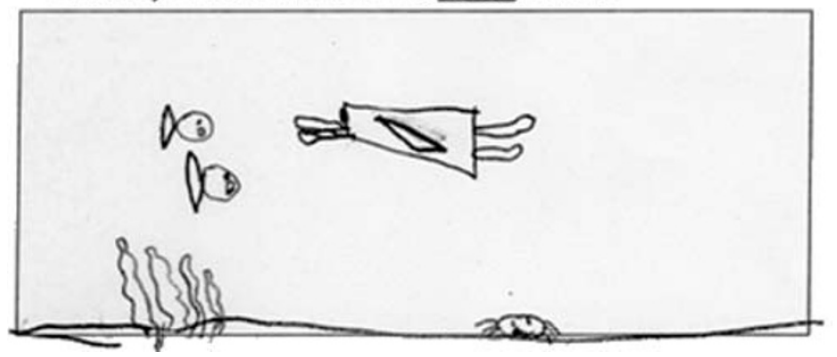

Fig. 8 An illustration of a modified bird adapted to an aquatic environment isms giving birth to live young and having a reason for nesting.

\section{Discussion}

Evolution is a complex topic that necessitates long-term exposure to comprehend fully. Recognizing this situation, the developers of state and national science standards recommend that evolution be part of the K-12 science curriculum starting at the early elementary levels (NRC 1996; NSTA 2002). To address these recommendations we developed and delivered two lessons that were specifically designed to address student achievement of two state science standards that focus on concepts of evolution. We sought to determine what early elementary students' lesson products could tell us about their learning of evolutionary science, to determine the effectiveness of our lessons for teaching evolution concepts, and to determine if early elementary students were capable of learning aspects of evolutionary theory.

Our lessons were designed to gather several student products used as evidence of their learning. These artifacts allowed us to address our research question concerning what information that could be garnered and used from early elementary students' products to determine the extent of their learning of evolutionary science. Our lessons provided an opportunity for the students to express their knowledge through modeling, drawing, and selected response activities. It is apparent from the products of these activities that students expressed an understanding of similarity and differences of various organisms. The exposure of the students' ability to communicate patterns of similarities and differences of a variety of organism indicates that students' products are useful forms of evidence for assessing student science learning. Furthermore, their products indicate that the majority achieved the goals of the lessons and through the expression of similarities and differences communicated some fundamental understanding of speciation and adaptation. Thus, the summarized answer to our research question is: student products are useful sources of evidence that reflect both their learning and understanding of evolution concepts.

In designing our standards-based lessons, we attended to recommendations calling for the creation of opportunities for young learners to think scientifically. More specifically, we included activities that required student engagement in guided inquiry and modeling. With support from the literature, we integrated these instructional approaches into our evolution science lessons (Eshach and Fried 2005; Metz 1995, 2004). The inclusion of these approaches led us to ask how effective guided inquiry and modeling would be in 
Fig. 9 The percent correct in noting the differences and similarities between Hesperornis and living birds

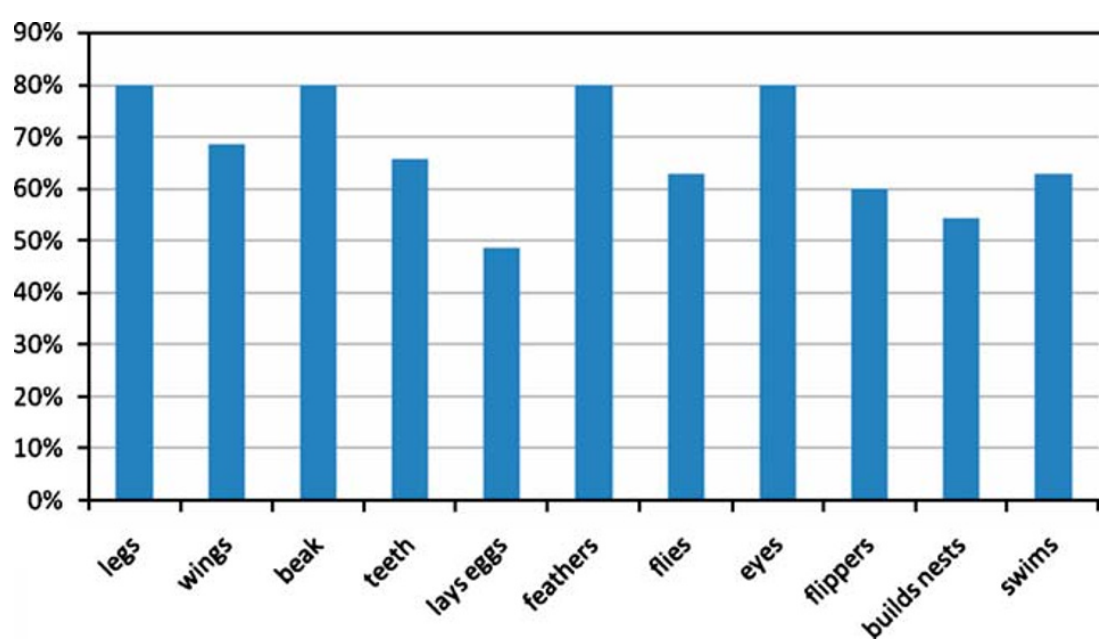

teaching concepts fundamental to learning speciation and adaptation to early elementary students. An examination of the students' products related to our guiding inquiry and modeling assignments indicates that young learners engaging in these activities can accomplish them but may need support. The second graders did seem to need less support than the kindergarteners, which may be reflective of the activities or reflective of differences in knowledge and experience. Regardless, the majority of students from both groups was able to successfully complete the modeling and guided inquiry assignments, the outcomes of which indicated that they perceived and were able to transfer patterns of similarity and differences. The perception and transfer of these patterns suggests that the students were able to use the guided inquiry and modeling activities to express their knowledge fundamental to grasping adaptation and speciation. Thus, it appears that modeling and guided inquiry, especially with support, are effective approaches for teaching early elementary students concepts of evolutionary biology.

Our overall goal was to heed the call to teach evolution concepts to early elementary students through the development and delivery of age- and developmentally-appropriate lessons. The relatively recent call for the inclusion of evolutionary content in the early elementary science curriculum warrants investigating the capabilities of young learners to grasp concepts fundamental to developing an understanding of speciation and adaptation. It is apparent from our results that students were able to successfully complete our lesson activities, which were designed to teach foundational knowledge required for learning abstract and more complex explanations of evolution. Student accomplishment of our learning goals reveals they are capable of learning simplified presentations of the concepts of speciation and evolution. This provides support for the development, delivery, and research of the effectiveness of additional lessons addressing evolution science standards in the early elementary grades.

Our results confirmed our hypothesis, which is made evident by the eagerness of all the participating students to answer questions, create models, and complete the learning activities. Students exhibited high levels of engagement, communicated activation of prior knowledge, and developed meaningful and representative models that led to their achievement of our lessons' learning goals. Teaching science to young learners is challenging (NRC 2007) and may be further impeded by views of developmental limitations of early elementary learners' cognitive abilities and constrained capacity to grasp aspects of abstract concepts (Metz 1995, 2004). However, the participating young learners displayed the levels of scientific thinking that are promoted as an important motivation for including science in the elementary curriculum (Eshach and Fried 2005). The students' responses to our lessons were consistent with Metz and the NRC. They were able to complete guided inquiry activities that reflect a certain level of abstract thinking. Furthermore, the recognition of patterns of similarity and difference and the transfer of those concepts to other activities reflect the application of reasoning and understanding of concepts.

There were several limitations to our study. Perhaps the most salient is the lack of a delayed post-test of student knowledge. The determination of student knowledge acquisition and understanding were based on their abilities to complete the lesson and transfer concepts between activities. Although effective for determining immediate outcomes, we did not assess the long-term influence of our lessons. This is an excellent direction for future research. Another limitation of our study was the lack of an ability to fully account for the students' prior knowledge. It is possible that the students did not 
learn new concepts from the lesson but were simply applying prior knowledge. However, conversations with the cooperating teachers suggest this was unlikely but still possible.

The teaching of evolution concepts in the early elementary grades is ripe with research opportunities. Future research might examine the longitudinal influence of a science lessons designed to teach evolution science to young learners; it might help determine student ability; it might help evaluate their grasp to retain and apply their knowledge and perceptions to more sophisticated contexts; and of concepts representative of the fundamentals of speciation and adaptation. Another direction that research might take is the investigation of the benefits and influence of a single lesson as compared to a series of lessons designed to meet the evolution science standards. Our lesson used a combination of instruction and hands-on activities that may not have been the most effective approach for teaching these concepts. Other instructional approaches or combinations of approaches may be more effective at establishing a foundation for learning more complex evolution concepts.

Overall, our investigation allowed us to answer our research questions, achieve the instructional goals of our lessons, and gather evidence to test our hypothesis. The successful implementation of the lessons and the positive student responses indicate that young learners are capable and eager to learn evolutionary science. Teaching biology concepts to primary students may be an important long-range step in bringing about change in the levels of understanding and acceptance of the theory of evolution. Introducing evolution concepts to early elementary grades is critical because this is a time when children are open to new ideas and are seeking evidence to test their theories of how the world works. Through providing young learners with experiences and activities that reflect the scientific perceptions of evolution, these students are more likely to develop accurate conceptions on which deeper understanding can be built as they progress in their education.

\section{Appendix A}

Similarities and Differences

\section{Kindergarten}

Overview: In this lesson groups of students will be provided with skeletal models of the feet of several different animals. They will then construct a "skeletal model foot" and then draw the organisms that the feet belong to.
Florida Sunshine State Learning Standard: SC.K. L.3.1-Observe and describe similarities and differences among different types of plants and among different types of animals.

Lesson concepts:

- Living things are alike in some ways and different in other ways.

- Form is linked to function.

Time: one class period

Grouping:

- Small group for model creation

- Individual for drawing organism in the model moving in their environment

- Whole class for presentation/discussion of similarities and difference in feet

Lesson background:

In order to live on planet Earth, all living things must surmount the same set of challenges - food acquisition, gas exchange, protection, locomotion, waste disposal, etc. The remarkable thing about living organisms is the wide variety of strategies used to solve the same problems, or solutions may be remarkably similar. Although hamsters get from place to place on four feet while snails slide around on a single "foot," the skeletal structures of the feet of walking animals are very similar. Even marine mammals" "flippers" have bone structures very similar to the feet of land mammals. There is no end to the discoveries that can be made when we start comparing living things to each other.

It is important to keep in mind that when we have children compare and sort living things, they are not classifying. Scientific classification of living things is based on common ancestry, which children do not have the experience or background knowledge to effectively accomplish.

Vocabulary: skeleton, bones, similarity, differences

Procedure:

1. Review the parts of a animal skeleton, and then specifically the foot (ten minutes)

2. Form groups of students, and provide each group with models or illustrations of the feet of a bird, a cat, a lizard, a monkey, and a manatee. Ask them to think about what is similar and what is different. (five to ten minutes)

(1). How many parts are there?

a. Can you name the parts?

(2). How are the skeletons the same?

(3). How are the skeletons different?

3. After examining the illustrations or models, give the groups of students popsicle sticks of different length 
and ask them to create a dog skeleton foot (two dimensional). (ten minutes)

4. After creating their model have each student draw a picture of the dog that "belongs" to the foot moving where it lives. (ten minutes)

5. Summarize with comparisons of feet skeletons other organisms such as the manatee, horse, mouse, and raccoon. (ten minutes)

Materials:

- Model of an animal skeleton

- A variety of animal feet skeletons-either models or illustrations (see list below)

- Popsicle sticks and tongue depressors of different lengths

- Paper and crayons or color pencils

Data collection - assessment of learning:

1. Photos of student models along with student explanations of the parts and what they do.

2. Drawings of the organisms moving in their environments, with student explanations.

Potential teacher follow-up activities

- Have students look at the similarity of flowers or fruit and note how similar and different.

- Have students bring in five different leaves, draw them and them share how they are similar and different.

- Discuss dogs and how they are similar and different, have everybody bring in a picture of a dog and make a dog collage.

\section{Appendix B}

\section{Alive and Extinct}

Birds Models

\section{Second Grade}

Overview: In this lesson students will create models of living birds and extinct birds and then use the models to discuss the similarity and differences to birds that are now extinct.

Learning Standard: SC.2.L.5.2 Recognize some organisms that lived long ago are similar to existing organisms today, but some have completely disappeared.

Lesson concepts:

- Birds are classified based on similar traits

- Birds live in a range of habitats
- Many life forms have gone extinct

- Many life forms look very similar to organisms that lived long ago

Time: one class period

Grouping:

- Small group for model creation

- Individual for model in environment drawing

- Whole class for presentation/discussion of bird evolution

Instructional background:

In the course of Earth's history, most bird-like forms have gone extinct or evolved into new forms. Some living birds closely resemble ancient forms, while others are very different from anything that came before. Use the OSC kits of model resources for students to build a model that may be found today and then draw the bird in its habitat. Repeat this process for a bird that lived long ago in the water. End activity with the presentation of specimens to talk about extinct life forms and similarities to birds today.

Teacher resources: related information is available from the following reliable web sites:

PBS: http://www.pbs.org/lifeofbirds/evolution/index. html

University of California Museum of Paleontology: http:// www.ucmp.berkeley.edu/diapsids/birds/birdfr.html

Vocabulary: living, extinct, similarity, differences, relative, ancestor

Procedure:

6. Review the parts of a bird by having students name as many of the parts as they can recall. Tell them they will be making a model of a bird out a variety of common objects, and they should think about what they know about how different birds look the same and how they look different. They should also think about where the birds live. (ten minutes)

7. Form groups of students, and provide each group with a variety of common objects and give them the task of making a two-dimentional model of a bird in five minutes. Remind them that they do not have to use ALL of the objects. (ten minutes)

8. After the creation of the model, have each student draw a picture of their bird in the environment in which the students think it would live. (ten minutes)

9. Then ask the students to make a different model of a bird that lives in the water. Again the students will use the provided objects and make a twodimentional model of a bird in five minutes. (ten minutes)

10. Again ask the students to draw a picture of their water bird in the environment in which they think it might live. (ten minutes) 
11. Present specimens to students of some different birds found today along with fossils (or models of fossils) of extinct water birds. Discuss what is similar and different. (ten minutes)

\section{Materials:}

Bins of common objects, drawing paper $(8.5 \times 11)$, crayons or color pencils.

Common objects might include: (this is partial)

\begin{tabular}{ll}
\hline - Tongue depressors & - Pipe cleaners \\
- Sections of garden hose & - Cotton balls \\
- Garden stakes & - Ribbon \\
- Plastic lids and bowls & - Styrofoam balls \\
- Modeling clay & - Pennies \\
- Fabric swaths & - CDs \\
- Aluminum foil & - Packing peanuts \\
- Tape & - String \\
- Marbles & - Blocks \\
- Sculpture remnants & - Cones and triangles \\
\hline
\end{tabular}

Data collection

The following will be collected to provide evidence of student knowledge and learning:

3. Photos of the "alive today bird" models along with student explanations of how the bird lives, eats, moves, and where it lives

4. Student drawings of their "alive today bird" model in the bird's environment

5. Photos of the "birds that live in water" models along with student explanations of how the bird lives, eats, moves, and where it lives

6. Student drawings of their "water bird" model in the bird's environment

7. Student comments on the similarity and differences between birds alive today and those that lived millions of years ago in the water

Teacher follow-up activities

- Assign students the task of drawing an animal alive today and one that looks similar but is extinct (from a provided list) and write down or draw what is similar and what is different.

- Provide the students with illustrations of alive and extinct organisms and have them identify them accordingly. Then discuss how they may have changed over time.

- Repeat the same sort of activities with lizards or amphibians and connect back to dinosaurs.

\section{Appendix C}

\section{Hesperornis gracilis}

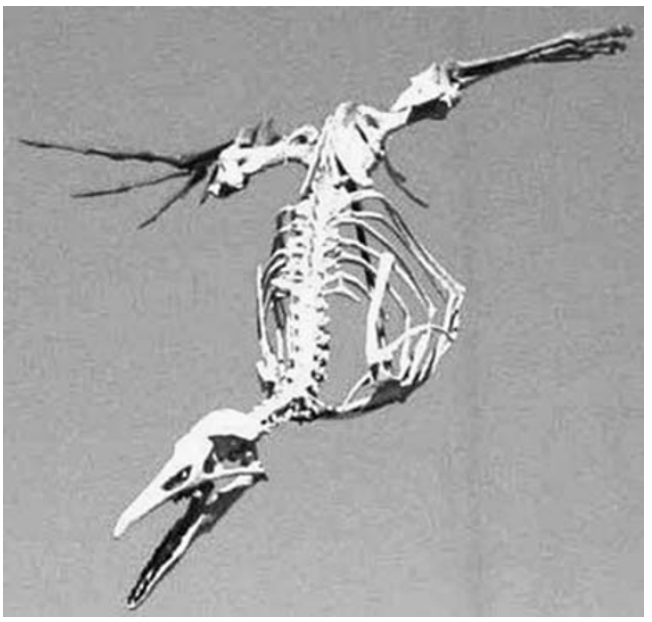

When I say "bird," what comes to your mind? What do you picture in your head of a bird? What does it take to be a bird? Wings? A nest full of eggs, high in a tree? The ability to fly?

Hesperornis is an early relative of birds - kind of a prehistoric penguin. It spent most of its life in the water-rarely if ever coming on shore. It was a strong swimmer-its thick leg bones and wide webbed toes gave it plenty of power for chasing down fish and tasty ammonites.

Catching food in the Cretaceous period was tough enough-but now factor in that you are moving at $20 \mathrm{mph}$ underwater with a pair of tweezers for a beak! But Hesperornis evolved a solution this problem - in a way that is not seen in any other birds today. Two rows of sharp, conical teeth to grip prey under the sharp beak tip.

- The teeth grew in grooves, not sockets like ours. If we lose a baby tooth, there's a gap for a little while, then the new teeth grow in. If Hesperornis lost a tooth, then the rest of its teeth would slide further forward.

Since Hesperornis spent most of its time in the water, some scientists believe that they gave live birth to their young, instead of laying eggs. It is also been suggested that if Hesperornis did lay eggs, it would have shuffled its body on shore and laid them in small coastal nests, somewhat like modern sea turtles. At times, Hesperornis made a tasty meal for mosasaurs. Fossilized Hesperornis bones have been found in the stomach area of fossilized mosasaur skeletons 


\section{References}

American Association for the Advancement of Science. Benchmarks for Science literacy. New York: Oxford University Press; 1993.

Au TKF, Chan CKK, Chan TK, Cheung MWL, Ho JYS, Ip GWM. Folkbiology meets microbiology: a study of conceptual and behavioral change. Cognitive Psychology. 2008;57(1):1-19.

Bransford J, Brown AL, Cocking RR, editors. How people learn: brain, mind, experience, and school. Washington, D.C.: National Academy Press; 1999.

Center on Educational Policy (2008). Instructional time in elementary schools a closer look at changes for specific subjects. Retrieved April 4, 2008 from: http://www.cep-dc.org/index. cfm? fuseaction=document. showDocumentByID\&nodeID $=1 \&$ DocumentID $=234$

Chen Z, Klahr D. All other things being equal: children's acquisition of the control of variables strategy. Child Development. 1999; 70:1098-120.

Dawkins R. The blind watchmaker: why the evidence of evolution reveals a universe without design. New York: Norton; 1996.

Duschl RA, Grady RE. Teaching scientific inquiry. Recommendations for research and implementation. Rotterdam: Sense publishers; 2008.

Eshach H, Fried MN. Should science be taught to early childhood? Journal of Science Education and Technology. 2005;14(3):31536.

Florida State Department of Education. Sunshine State Science Standards. Tallahassee: Florida Department of Education; 2008.

Gallup, G. (2008). Evolution, creationism and intelligent design. Retrieved October 17, 2008, from http://www.gallup.com/poll/ 21814/Evolution-Creationism-Intelligent-Design.aspx

Gould SJ. The structure of evolutionary theory. Cambridge: Harvard University Press; 2002.

Gross PR, Goodenough U, Lerner LS, Haack S, Schwartz M, Schwartz R, Finn CE. The state of state science standards. Washington, D.C.: Thomas B. Fordham Institute; 2005. Retrieved September 27, 2008 from: http://www.edexcellence.net/ institute/publication/publication.cfm?id=352.

Hatano GY, Inagaki K. Young childrens naive theory of biology. Cognition. 1994;50(1-3):171-88.

Inagaki K, Hatano G. Vitalistic causality in young children's naive biology. Trends in Cognitive Sciences. 2004;8(8):356-62.

Inagaki K, Hatano G. Young children's conception of the biological world. Current Directions in Psychological Science. 2006;15 (4):177-81.

Inhelder B, Piaget J. Growth of logical thinking: from childhood to adolescence. New York: Basic Books; 1958.

Kelemen D. The scope of teleological thinking in preschool children. Cognition. 1999;70:241-72.

Kuhn D. Children and adults as intuitive scientists. Psychological Review. 1989;96:674-89.

Kuhn D, Pearsall S. Developmental origins of scientific thinking. Journal of Cognition and Development. 2000;1:113-29.

Lehrer R, Schauble L. Modeling natural variation through distribution. American Educational Research Journal. 2004;41(3):635-79.

Levitt KE. An analysis of elementary teachers' beliefs regarding the teaching and learning of science. Science Education. 2001;86:1-22.

Marini Z, Case R. The development of abstract reasoning about the physical and social world. Child Development. 1994;65(1):147-59.

Metz KE. Children's understanding of scientific inquiry: their conceptualization of uncertainty in investigations of their own design. Cognition and Instruction. 2004;22(2):219-90.
Metz KE. Reassessment of developmental constraints on children's science instruction. Review of Educational Research. 1995;65: 93-127.

Miller KR. Finding Darwin's God: a scientist's search for common ground between God and evolution. New York: Cliff Street Books, HarperCollins; 1999.

Nadelson LS, Sinatra GM. Educational psychologists' knowledge of evolution. Paper presented at the annual meeting of the American Psychological Association, Boston; 2008.

National Academy of Sciences. Science, evolution, and creationism. Washington D.C.: National Academy Press; 2008.

National Academy of Sciences. Teaching about evolution and the nature of science. Washington, D.C.: National Academy Press; 1998.

National Research Council. Taking science to school: learning and teaching science in grades K-8. In: Duschl RA, Schweingruber HA, Shouse AW, editors. Washington, D.C.: The National Academies Press; 2007.

National Research Council. Inquiry and the national science education standards: a guide for teaching and learning. Washington, DC: National Academy Press; 2000.

National Research Council. National science education standards. Washington, DC: National Academy Press; 1996.

National Science Teachers Association. An NSTA position statement: elementary school science. Arlington: NSTA; 2002.

Schwab JJ. The teaching of science as enquiry. In: Schwab JJ, Brandwein P, editors. The teaching of science. Cambridge: Harvard University Press; 1962.

Skamp K, Mueller A. Student teachers' conceptions about effective elementary science teaching: a longitudinal study. International Journal of Science Education. 2001;23:331-51.

Smith MU. Counterpoint: belief, understanding, and the teaching of evolution. Journal of research in science teaching. 1994;31 (5):591-7.

Smith MU, Siegel H. Knowing, believing, and understanding: what goals for science education? Science and Education. 2004;13 (6):553-82.

Solomon GEA. Birth, kind and naive biology. Developmental Science. $2002 ; 5(2): 213-8$.

Solomon GEA, Johnson SC. Conceptual change in the classroom: teaching young children to understand biological inheritance. British Journal of Developmental Psychology. 2000;18:81-96.

Southerland SA, Sinatra GM, Matthews MR. Belief, knowledge, and science education. Educational Psychology Review. 2001;13:32551.

Spillane JP, Callahan KA. Implementing state standards for science education: what district policy makers make of the hoopla. Journal of Research in Science Teaching. 2000;37(5):401-25.

Springer K. Young children's understanding of a biological basis for parent-offspring relations. Child Development. 1996;67(6):2841-56.

Tosun $\mathrm{T}$. The beliefs of pre-service elementary teachers toward science and science teaching. School Science \& Mathematics. 2000;100 (7):376-82.

Venville G, Donovan J. Developing Year 2 students' theory of biology with concepts of the gene and DNA. International Journal of Science Education. 2007;29(9):1111-31.

Vygotsky LS. In: Cole M, John-Steiner V, Scribner S, Souberman E, editors. Mind in society: the development of higher psychological processes. Cambridge: Harvard University Press; 1978.

Yates GCR, Chandler M. Where have all the skeptics gone? Patterns of new age beliefs and anti-scientific attitudes in preservice elementary teachers. Research in Science Education. 2001;30: 377-87. 